Article

\title{
Mercury-induced Phytotoxicity and Responses in Upland Cot- ton (Gossypium hirsutum L.) Seedlings
}

\author{
Lei Mei 1,*, Yueyi Zhu 1, Xianwen Zhang 2, Xiujuan Zhou 1, Zhentao Zhong 1, Huazu Li 1, Yingjun Li 3, Xiaohu Li ${ }^{3}$, \\ Muhammad Khan Daud ${ }^{4}$, Jinhong Chen ${ }^{1}$ and Shuijin Zhu ${ }^{1, *}$ \\ 1 Institution of Crop Science, Zhejiang University, Hangzhou 310058, China; 21916018@zju.edu.cn; \\ 414077576@qq.com; 21816016@zju.edu.com; 12016016@zju.edu.cn; jinhongchen@zju.edu.cn \\ 2 The Agricultural Experiment Station, Zhejiang University, Hangzhou 310058, China; bestzxw@163.com \\ 3 College of Plant Science and Technology, Huazhong Agricultural University, 430070 Wuhan, China; \\ yingjun@mail.hzau.edu.cn; 647386118@qq.com \\ 4 Department of Biotechnology and Genetic Engineering, Kohat University of Science and Technology, Kohat \\ 26000, Pakistan; mkdaud@yahoo.com \\ * Correspondence: meileihzruk@gmail.com (L. M.); shjzhu@zju.edu.cn (S. Z.)
}

\begin{abstract}
Cotton is a potential and excellent candidate to balance both agricultural production and remediation of mercury-contained soil, as its main production fiber hardly involve into food chains. However, there is known rarely about the tolerance and response to $\mathrm{Hg}$ environments in cotton. In this study, The biochemical and physiological damages, in response to mercury ( $\mathrm{Hg})$, were investigated in upland cotton seedlings. The results on cottonseeds germination, indicated the germination rate were suppressed by high $\mathrm{Hg}$ levels, as the decrease of percentage was more than $10 \%$ at 1000 $\mu \mathrm{M} \mathrm{Hg}$. Shoots and roots' growth were significantly inhibited above $10 \mu \mathrm{M} \mathrm{Hg}$. The inhibitor rates (IR) in fresh weight were close between shoots and roots, whereas that in dry weight the root growth was more obviously influenced by $\mathrm{Hg}$. In comparison of organs, the growth inhibition ranked as root $>$ leaf $>$ stem. The declining of translocation factor (TF) opposed the $\mathrm{Hg}$ level even as low to 0.05 at $50 \mu \mathrm{M} \mathrm{Hg}$. The assimilation of cotton plants was affected negatively by Hg toxicity, as evidenced from the performances on photosynthesis pigments (chlorophyll $a$ and $b$ ) and gas exchange (Intercellular $\mathrm{CO}_{2}$ concentration $(\mathrm{Ci}), \mathrm{CO}_{2}$ assimilation rate $(\mathrm{Pn})$ and stomatal conductance $(\mathrm{Gs})$ )) Sick phenotypes on leaf surface included small white zone, shrinking and necrosis. Membrane lipid peroxidation and leakage were $\mathrm{Hg}$ dose-dependent as indicated by malondialdehyde (MDA) content and relative conductivity (RC) values in leaves and roots. More than $10 \mu \mathrm{M} \mathrm{Hg}$ damaged antioxidant enzyme system in both leaves and roots $(p<0.05)$. Concludingly, $10 \mu \mathrm{M} \mathrm{Hg}$ post negative consequences to upland cotton plants in growth, physiology and biochemistry, whereas high phytotoxicity and damage appeared at more than $50 \mu \mathrm{M} \mathrm{Hg}$ concentration.
\end{abstract}

Keywords: Upland cotton (Gossypium hirsutum L.); Mercury stress; Phytotoxicity; Physiological and biochemical response

\section{Introduction}

Heavy metal (HM) pollution, as a global problem affecting terrestrial and aquatic environments, as well as posts a potential threat to human health via the food chains. Meanwhile, excessive heavy metal concentrations in soils, resulted in yield reduction and poor quality of crop products (Cao et al. 2014). Mercury (Hg), is one of the most toxic HM because of its easy bioaccumulation in living bodies (Suszcynsky and Shann 1995). Hg may enter to agricultural soil through various anthropogenic activities including fertilizers, pesticides, sludge, lime and manure. It exists in nature in forms like elemental mercury, ionic mercury, methyl mercury, mercury sulfide and mercury hydroxide. In all sorts of mercury, ionic mercury is the predominant toxic form (Han et al. 2002; Heaton et al. 
2005). In plant, the toxic action of $\mathrm{Hg}$ is first of done on the roots, which take up $\mathrm{Hg}$ directly in an efficient manner (Han et al. 2006). While entering the root cells, $\mathrm{Hg}$ may bind to the water channel proteins of root cells and thus causes physical obstruction to water flowing, consequently affects the transpiration in plants (Maggio and Joly 1995; Zhang and Tyerman 1999). Furthermore, it has also been reported that Hg suppresses photosynthesis, chlorophyll synthesis, as well as uptake and transport of nutrients. $\mathrm{Hg}$ is considered to inhabit the activity of the NADPH: protochlorophyllide oxidoreductase (POR), which play key roles in photosynthesis, consequently affect plant growth involving in biomass (Lenti et al. 2002). Sahu et al. (2012) evaluated the oxidative damages response to $\mathrm{Hg}$ concentrations in wheat, represent lower and higher $\mathrm{Hg}$ concentration induced and repressed antioxidant enzymes activities separately, which supported the opinion that $\mathrm{Hg}$ can boost the formation of reactive oxygen species (ROS) and consequently post more serious oxidative stress on plant cell.

Cotton (Gossypium spp.), is the most important source of natural fiber as well as a key source of edible oil in the world. Due to its hard-wooden nature, cotton present relatively multiple resistances to abiotic stress (Jiang et al. 2006). Previous works regarding HMs stress on cotton, reveal varied behavior of cotton cultivars towards various toxic HMs like cadmium $(\mathrm{Cd})$, Chromium $(\mathrm{Cr})$, Copper $(\mathrm{Cu})$, Lead $(\mathrm{Pb})$. Under sorts of HM with concentrations, there appeared anomalies in cotton plants. The performance could be detected such as reduction in germination at higher levels of metals, decline in the biometric parameters like root and shoot length, or fresh and dry biomasses as well as waving on biochemical substances (Daud et al., 2013; 2015; 2016; Khan et al., 2013; Mei et al., 2015). Regarding the cotton behaviour towards $\mathrm{Hg}$, no such study has been so far conducted. Keeping in view of the global usage of $\mathrm{Hg}$ in various industries, the present experiment was designed with the aim to investigate the toxic effects of mercury on upland cotton by studying various physiological and biochemical parameters.

\section{Results}

\subsection{Effects of Mercury on Cotton Seeds Germination}

In laboratory experiments, a mercury concentration ranged from 0 to $10000 \mu \mathrm{M}$, was employed in order to test the performances on cottonseed germination. Elongation of seed shoot and color alternatives, paralleling with the percentage of germination, were studied. Changes in morphology and percentage of seed germination were obvious and presented as Figure 1 and 2. Overall, higher $\mathrm{Hg}$ concentrations treatment depressed seed shoot elongation, darken the seeds surface and reduced percentage of germination, comparing with low levels. In details, 1 and $10 \mu \mathrm{M} \mathrm{Hg}$ did not affect seed shoot elongation, whereas obvious variations could be observed in the doses 100, 1000 and $10000 \mu \mathrm{M}$. The seed surface color was white both in the control and treatments of $100 \mu \mathrm{M} \mathrm{Hg}$. However, in the group of 1000 and $10000 \mu \mathrm{M}$, the seed surface turned grown, which was considered as sick. The percentage of germination were tested in a course of $72 \mathrm{~h}$. As revealed in Figure 2, there were not significant variation $(p<0.05)$ in germination percentage from the control to 100 $\mu \mathrm{M}$, and they maintained percentages above $90 \%$ for 72 hours. Nevertheless, the germination percentage declined starting from $1000 \mu \mathrm{M} \mathrm{Hg}$, and the percentage decreased to $80 \% \sim 90 \%$. At $10000 \mu \mathrm{M} \mathrm{Hg}$, the germination percentage sharply dropped to below $10 \%$. 


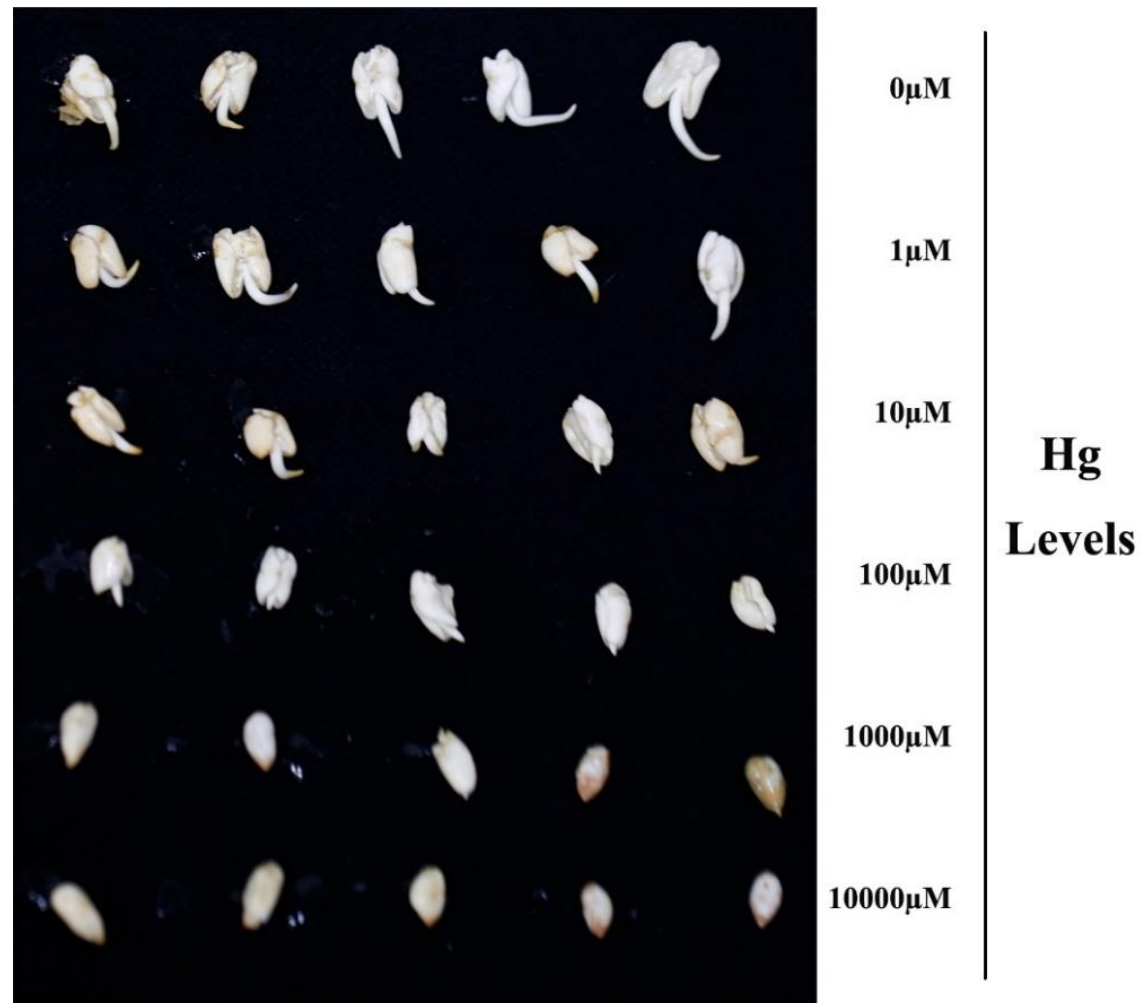

Figure 1. Morphology on germination of de-coated seeds TM-1 under Hg treatments. De-coated seeds exposed to $\mathrm{Hg}^{2+}$ solution with gradient $0,1,10,100,1000$ and $10000 \mu \mathrm{M}$, which were presented from upper to lower rows respectively.

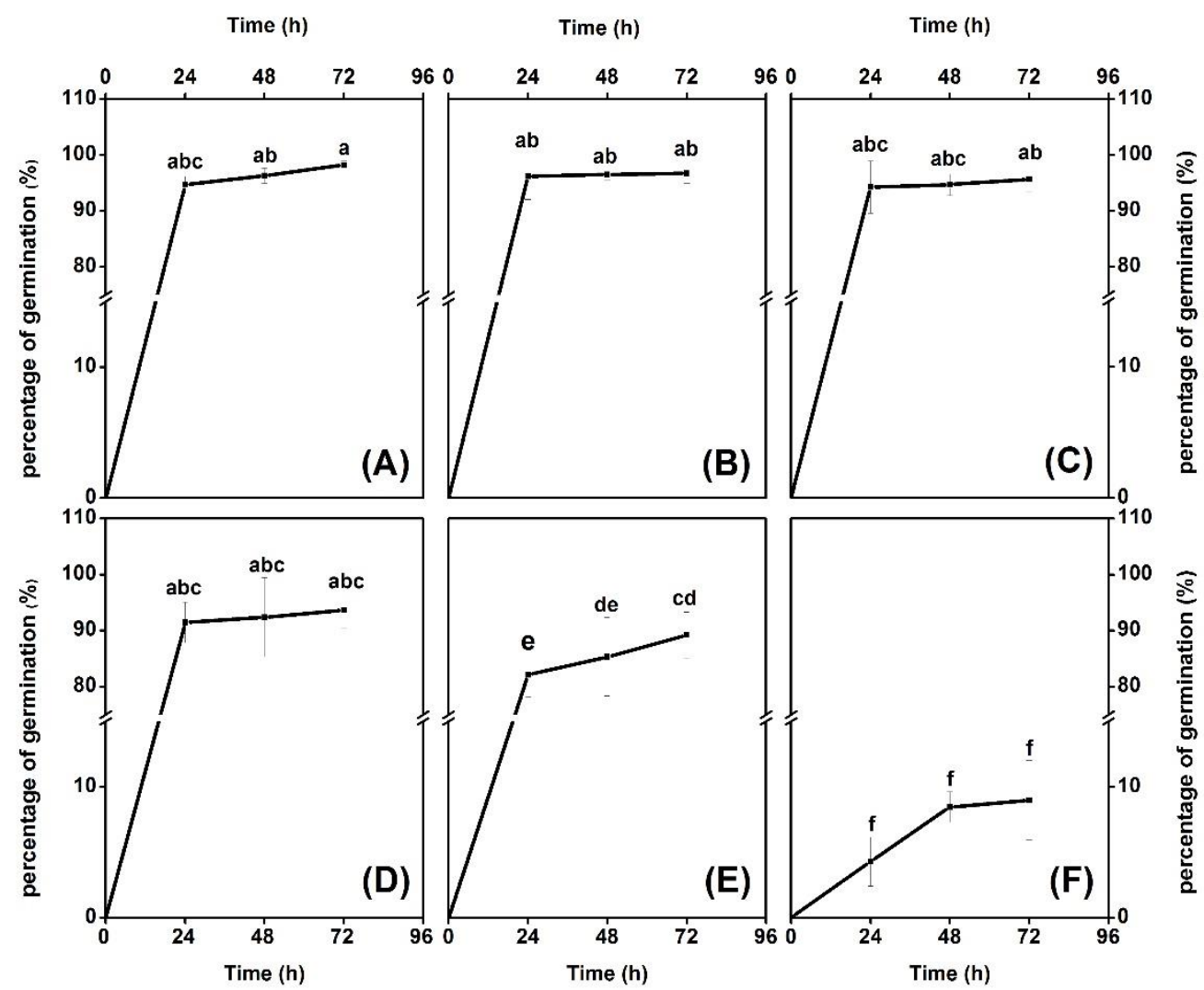

Figure 2. Germination rate of de-coated cottonseeds under $\mathrm{Hg}$ concentrations during a course of 72 h. (A) (F): De-coated cottonseeds exposed to Hg2+ solution with concentration at 0, 1, 10, 100, 1000 and $10000 \mu \mathrm{M}$ respectively, and the germination experiment was conducted under shaking 
condition at $130 \mathrm{rpm}$ and $28{ }^{\circ} \mathrm{C}$ in dark. The percentages of germination were determined at 0,24 , 48 and 72 hours. Error bars represent SD value $(n=3)$. Different letters indicate significant differences $(p<0.05)$.

\subsection{Growth and Mercury Distribution}

Cotton seedlings weight declined after $\mathrm{HgCl}_{2}$ treatment for a week. The reduction, in fresh and dry weight of both shoots and roots, was dose-dependent (Table 1). In shoots, there was no significance in fresh weight between the control and $1 \mu \mathrm{M} \mathrm{Hg}(p<0.05)$. At $10 \mu \mathrm{M} \mathrm{Hg}$, the fresh weight mean value of the shoots was $65.55 \mathrm{~g}$, where the inhibitory rate was $18.8 \%$. When the concentration over $50 \mu \mathrm{M}$, the inhibitory rate seemed to reach maximum limit, as 36.26 and $37.32 \%$ were quite close each other and appeared at 50 and $100 \mu \mathrm{M} \mathrm{Hg}$ treatments separately. Regarding to the dry weight in shoots, it can be affected by elevated $\mathrm{Hg}$ concentrations and exhibited analogous trends with in fresh weight, even though there was no statistical difference at $10 \mu \mathrm{M} \mathrm{Hg}$. Correspondingly, the growth inhibition of both fresh and dry weight in roots, was in a dose-dependent manner with increased Hg level. What's more, the significant IR change (comparing with the controls) on fresh and dry weight of roots, was begin at $10 \mu \mathrm{M} \mathrm{Hg}$, and the IR value was over 32.10 at 50 and $100 \mu \mathrm{M} \mathrm{Hg}$. Overall, the cotton seedlings treated by $10 \mu \mathrm{M} \mathrm{Hg}$ for a week will appear significant growth inhibition and inhibitory upper limit appeared at approximate $50 \mu \mathrm{M} \mathrm{Hg}$. Comparing to shoots as well as fresh weight separately, the growth of relevant roots and dry weight was easier to be suppressed by Hg toxicity.

Mercury was accumulated in all organs involved in leaves, stems and roots after the exogenous treatments (Table 2). The roots concentrated most $\mathrm{Hg}$ content, followed by leaves and stems. The concentration index ranged from 1 58.89, 1 7.22 and 1 4.02 in those 3 sorts of organs respectively and orderly. As a whole on means data, the ability of $\mathrm{Hg}$ concentration in roots was 8 and 16 folds as that in leaves and stems separately. With the increased $\mathrm{Hg}$ concentrations, the translocation factor in cotton seedlings decreased. At 50 and $100 \mu \mathrm{M} \mathrm{Hg}$, the translocation factor value declined to 0.05 and 0.06 , which represented the limit of $\mathrm{Hg}$ translocation.

Table 1. Effects of Hg2+ levels on growth in shoots and roots.

\begin{tabular}{|c|c|c|c|c|c|c|c|c|}
\hline \multirow[b]{2}{*}{$\begin{array}{c}\mathrm{Hg}^{2+} \\
\text { Treatment } \\
(\mu \mathrm{M} / \mathrm{L})\end{array}$} & \multicolumn{4}{|c|}{ Shoots } & \multicolumn{4}{|c|}{ Roots } \\
\hline & $\begin{array}{c}\text { Fresh } \\
\text { Weight }\end{array}$ & $\begin{array}{c}\text { IR } \\
(\text { FW) } \\
(\%) \\
\end{array}$ & $\begin{array}{c}\text { Dry } \\
\text { Weight }\end{array}$ & $\begin{array}{c}\text { IR } \\
(\mathrm{DW}) \\
(\%) \\
\end{array}$ & $\begin{array}{c}\text { Fresh } \\
\text { Weight }\end{array}$ & $\begin{array}{c}\text { IR } \\
(\mathrm{FW}) \\
(\%) \\
\end{array}$ & $\begin{array}{c}\text { Dry } \\
\text { Weight }\end{array}$ & $\begin{array}{c}\text { IR } \\
(\mathrm{DW}) \\
(\%)\end{array}$ \\
\hline 0 & $\begin{array}{c}80.73 \pm 1.22 \\
a\end{array}$ & 0 & $6.76 \pm 0.69 a$ & 0 & $21.62 \pm 0.06 \mathrm{a}$ & 0 & $\begin{array}{c}1.91 \pm 0.28 \\
\mathrm{a}\end{array}$ & 0 \\
\hline 1 & $\begin{array}{c}79.89 \pm 1.97 \\
a\end{array}$ & 1.04 & $6.54 \pm 0.44 \mathrm{a}$ & 3.25 & $20.78 \pm 1.03 a$ & 3.89 & $\begin{array}{c}1.81 \pm 0.10 \\
\mathrm{a}\end{array}$ & 5.24 \\
\hline 10 & $\begin{array}{c}65.55 \pm 5.37 \\
b\end{array}$ & 18.8 & $\begin{array}{c}5.95 \pm 0.69 \\
a b\end{array}$ & 11.98 & $17.58 \pm 1.36 b$ & 18.69 & $\begin{array}{c}1.51 \pm 0.13 \\
b\end{array}$ & 20.94 \\
\hline 50 & $\begin{array}{c}51.42 \pm 3.23 \\
\text { c }\end{array}$ & 36.26 & $5.42 \pm 0.11 b$ & 19.82 & $14.68 \pm 1.90 \mathrm{c}$ & 32.10 & $\begin{array}{c}1.07 \pm 0.15 \\
\mathrm{c}\end{array}$ & 43.98 \\
\hline 100 & $\begin{array}{c}50.58 \pm 4.14 \\
\mathrm{C} \\
\end{array}$ & 37.32 & $5.40 \pm 0.10 b$ & 20.19 & $13.91 \pm 0.69 c$ & 36.16 & $\begin{array}{c}0.94 \pm 0.07 \\
\mathrm{C}\end{array}$ & 49.21 \\
\hline
\end{tabular}

Error bars represent SD value $(n=3)$ and different letters indicate significant differences $(p<0.05)$.

Table 2. Mercury distributions in tissues and their concentration and translocation in seedlings.

\begin{tabular}{cccccccc}
\hline $\mathbf{H g}^{2+}$ & \multicolumn{2}{c}{ Hg concentration $(\mu \mathrm{gg}-1 \mathrm{DW})$} & \multicolumn{2}{c}{ CI (Concentration Index) } & TF (Translocation \\
$\begin{array}{c}\text { Treatment } \\
\mathbf{s}(\boldsymbol{\mu M})\end{array}$ & Leaves & Stems & Root & Leaves & Stems & Roots & factor) \\
\hline $\mathbf{0}$ & $\begin{array}{c}1.45 \pm 0.10 \\
\mathrm{a}\end{array}$ & $1.63 \pm 0.28$ a & $5.16 \pm 0.05 \mathrm{a}$ & 1.00 & 1.00 & 1.00 & 0.60 \\
\hline
\end{tabular}




\begin{tabular}{|c|c|c|c|c|c|c|c|}
\hline 1 & $\begin{array}{c}2.23 \pm 0.12 \\
b\end{array}$ & $2.28 \pm 0.19 b$ & $28.60 \pm 0.36 b$ & 1.54 & 1.40 & 5.54 & 0.16 \\
\hline 10 & $\begin{array}{c}3.86 \pm 0.10 \\
b\end{array}$ & $2.42 \pm 0.01 c$ & $54.81 \pm 0.33 c$ & 2.66 & 1.48 & 10.62 & 0.11 \\
\hline 50 & $\begin{array}{c}9.37 \pm 0.45 \\
c\end{array}$ & $4.05 \pm 0.06 \mathrm{~d}$ & $\begin{array}{c}288.23 \pm 20.75 \\
\mathrm{~d}\end{array}$ & 6.46 & 2.48 & 55.86 & 0.05 \\
\hline 100 & $\begin{array}{c}10.47 \pm 0.27 \\
\mathrm{~d}\end{array}$ & $6.56 \pm 0.01 \mathrm{e}$ & $\begin{array}{c}303.89 \pm 11.58 \\
\mathrm{~d}\end{array}$ & 7.22 & 4.02 & 58.89 & 0.06 \\
\hline
\end{tabular}

Error bars represent SD value $(n=3)$ and different letters in same group indicate significant differences $(p<0.05)$.

\subsection{Effects of Mercury on Cotton Assimilation}

The growth of treated plants was inhibited under $\mathrm{Hg}$ stress, may indicate the decline on assimilations. The leaf surface phenotypes, as well as pigments and gas exchange involved in photosynthesis were studied. Much serve sick phenotype appeared in higher $\mathrm{Hg}$ concentration (Figure 3). At $10 \mu \mathrm{M} \mathrm{Hg}$, small white zone emerged on the leaf upper surface, whereas obvious necrosis and shrinking happened at 50 and $100 \mu \mathrm{M} \mathrm{Hg}$. The leaf health extent seemed to inversely synchronize to the inhibitory rate depending on $\mathrm{Hg}$ levels.

The mean amounts of photosynthesis pigments, chlorophyll a and $b$, showed a similar declined trend exposure to higher $\mathrm{Hg}$ pollutant (Figure 4). Chlorophyll a decreased to $98.8 \%, 74.0 \%, 53.5 \%$ and $47.2 \%$ at $1,10,50$ and $100 \mu \mathrm{M} \mathrm{Hg}$ concentration respectively in comparison with the control. Meanwhile, $93.2 \%, 74.6 \%, 51.5 \%$ and $36.9 \%$ decline were found in chlorophyll $\mathrm{b}$ as compared with the control. The total chlorophyll content comprised chlorophyll a plus b, exhibited the declining trends. In comparison to the control, the total chlorophyll reduced to $94.1 \%, 74.5 \%, 51.8 \%$ and $38.5 \%$ at $\mathrm{Hg}$ treatments of 1,10 , 50 and $100 \mu \mathrm{M}$ orderly.

Determination on leaf gas exchange parameters must help to track photosynthesis efficiency influenced by $\mathrm{Hg}$ stress (Figure 5). Compared with the control value 283.54 $\mu \mathrm{mol}^{*}$ mol-1, Ci was increased to $290.34,340.15,380.31$ and $395.21 \mu \mathrm{mol}^{*} \mathrm{~mol}-1$ corresponding 1, 10, 50 and $100 \mu \mathrm{M} \mathrm{Hg}$ treatments, respectively. A significant reduction in Gs was noted at 50 and $100 \mu \mathrm{M} \mathrm{Hg}$ treatments, and those were decreased to $67.11 \%$ and $53.95 \%$ in comparison to the control. On the contrary, Gs value in 1 and $10 \mu \mathrm{M} \mathrm{Hg}$ treatments didn't present significant increase than the control (Figure 5 (B)). Concerning Pn, there was no significant difference between $1 \mu \mathrm{M} \mathrm{Hg}$ and the control. However, profound value gaps on Pn were showed at 10, 50 and $100 \mu \mathrm{M} \mathrm{Hg}$, as reduced to $49.75 \%, 19.54 \%$ and $12.59 \%$ separately.

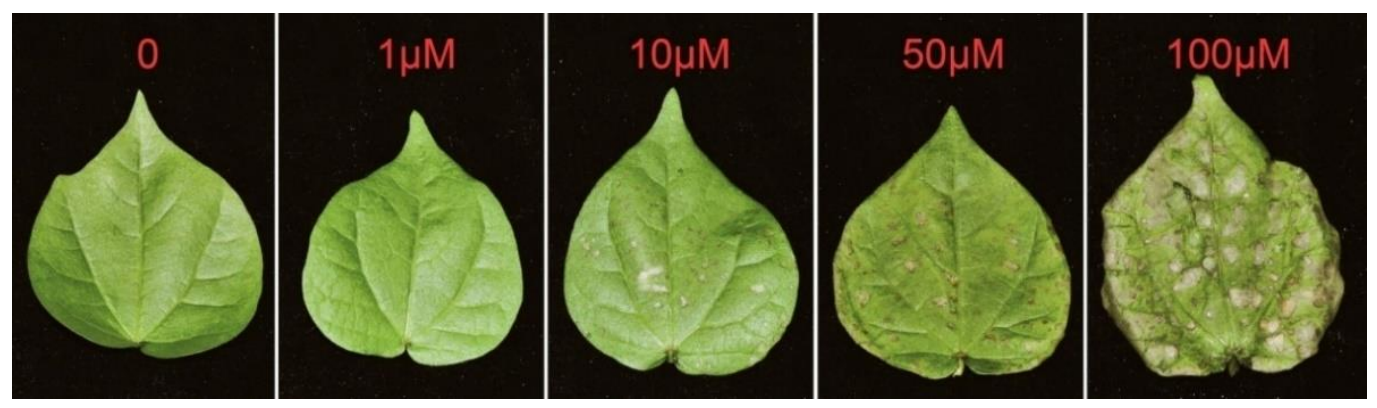

Figure 3. morphological leaves responding to $\mathrm{Hg}$ levels from $0,1,10,50$ and $100 \mu \mathrm{M}$. 


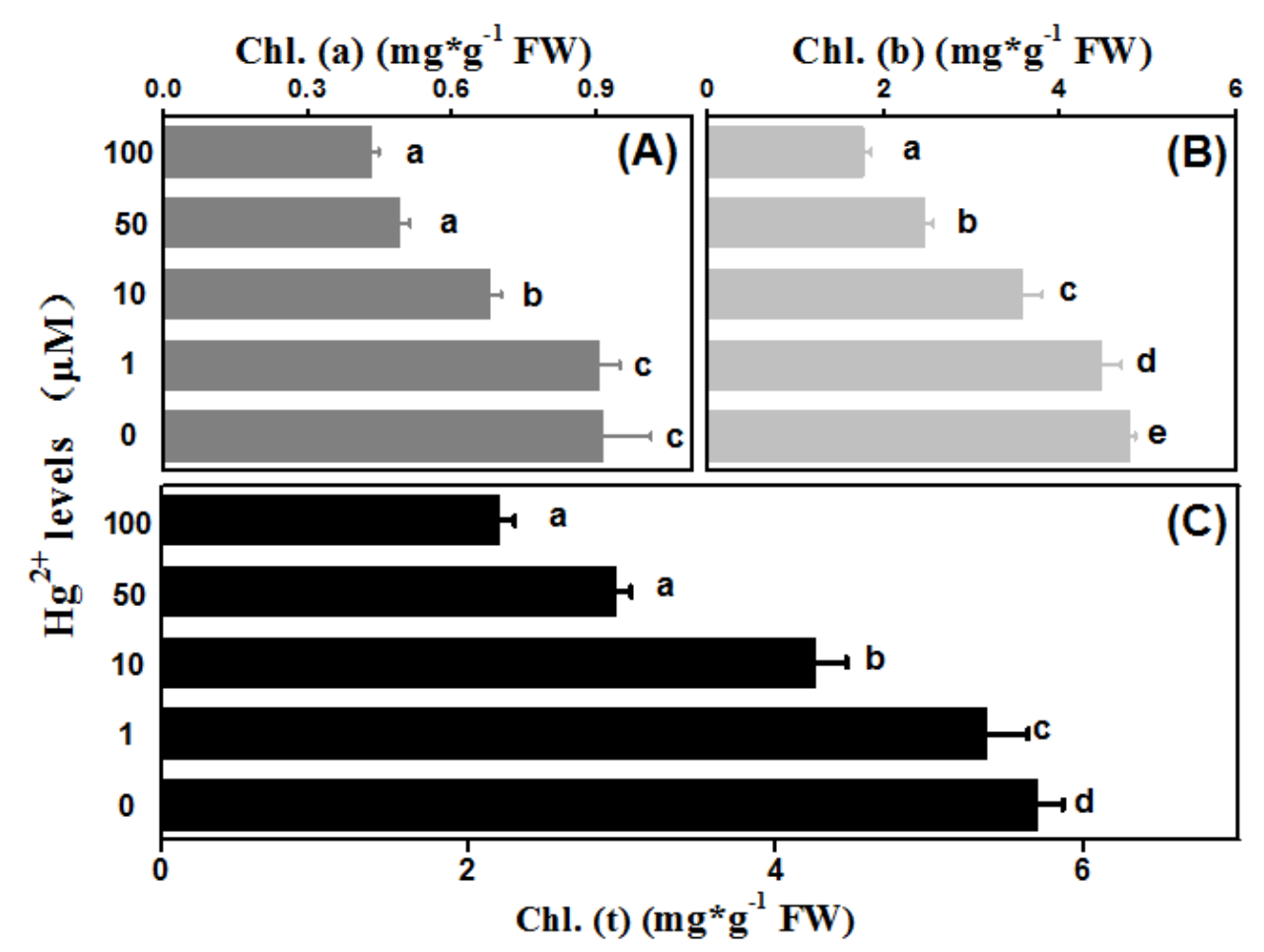

Figure 4. Pigment content in leaves under stress from Hg levels. (A) (C): Chlorophyll a, Chlorophyll $\mathrm{b}$ and total Chlorophyll contents, as abbreviated to Chl. (a), Chl. (b) and Chl. (t), is showed respectively. Error bars represent SD value $(n=3)$. Different letters indicate significant differences $(p<0.05)$.
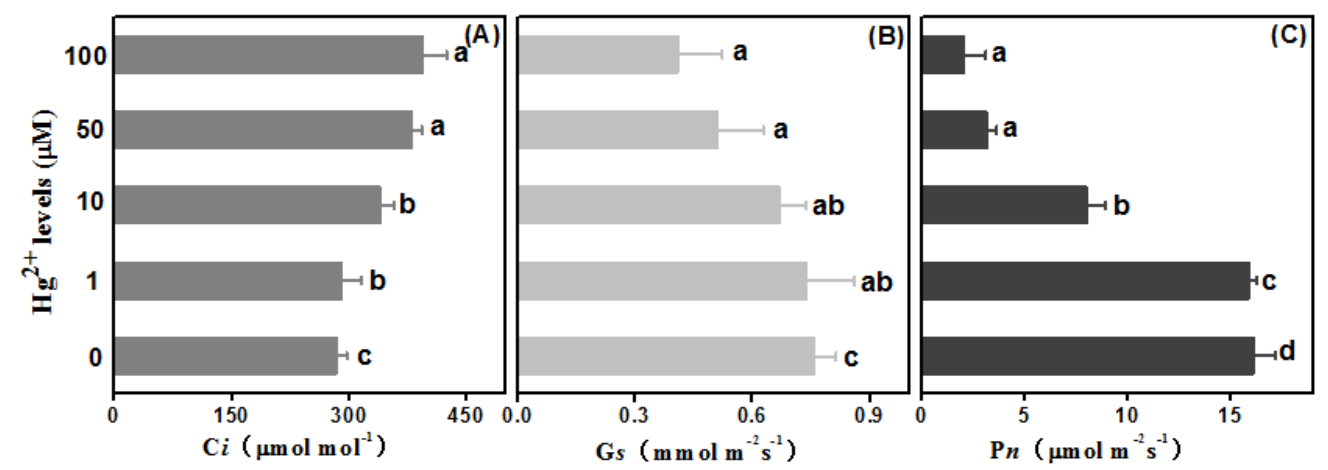

Figure 5. Gas exchange in leaves under stress from $\mathrm{Hg}$ levels. The left, center and right column is exhibited as the intercellular $\mathrm{CO} 2$ concentration (Ci), stomatal conductance (Gs) and CO2 assimilation rate $(\mathrm{Pn})$ respectively. Error bars represent SD value $(n=3)$. Different letters indicate significant differences $(p<0.05)$.

\subsection{Membrane Lipid Peroxidation and Leakage}

Accumulation of Malondialdehyde (MDA), as an key indicator of membrane lipid peroxidation, is commonly employed to evaluate cell injury under stresses (Chaudhuri and Choudhuri, 1993). MDA has been induced in both leaves and roots with the raising of treated $\mathrm{Hg}$ concentrations. As a whole, MDA accumulations in leaves were estimated 6 folds on average as much as that in roots (Figure 6). In leaves, amounts of MDA were increased apparently to $1.30,1.35$ and 1.46 times at 10,50 and $100 \mu \mathrm{M} \mathrm{Hg}$ treatments respectively in comparison with the control, whereas those increased to 1.54, 1.80 and 2.28 times in roots correspondingly.

Effects of variable Hg stresses on electrolyte leakage (EL), in both leaves and roots, were investigated via relative conductivity (RC) (Table 3). Mercury stress induced increase of electrolyte leakage significantly. In leaves, the RC value in the control was 
$15.54 \%$, and that was $15.85 \%, 30.30 \%, 53.95 \%$ and $78.36 \%$ at $1,10,50$ and $100 \mu \mathrm{M} \mathrm{Hg}$ respectively. In roots, correspondingly, RC was 35.22\%, 38.64\%, 52.10\% and $54.01 \%$ at $\mathrm{Hg}$ treatments, which were significantly much more than that in the control as value $20.21 \%$.

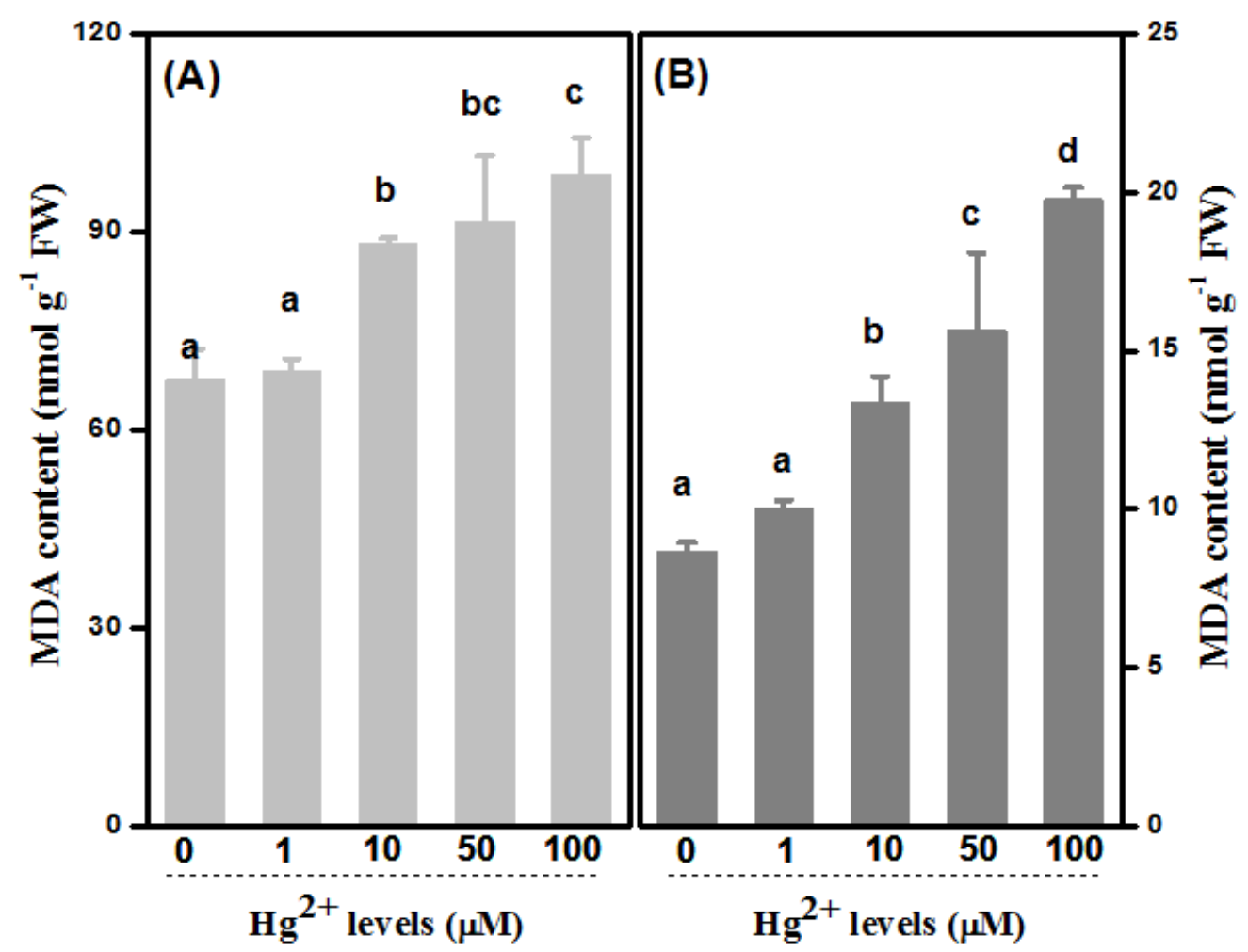

Figure 6. MDA content under $\mathrm{Hg}$ levels in leaves and roots. (A): MDA content under $\mathrm{Hg}^{2+}$ levels in leaves; (B): MDA content under $\mathrm{Hg}^{2+}$ levels in roots. Error bars represent SD value $(n=3)$ and different letters indicate significant differences $(p<0.05)$.

Table 3. Effects of $\mathrm{Hg}^{2+}$ levels on relative conductivity (RC) in leaves and roots.

\begin{tabular}{ccc}
\hline $\begin{array}{c}\mathbf{H g}^{2+} \mathbf{l e v e l s} \\
(\boldsymbol{\mu M})\end{array}$ & \multicolumn{2}{c}{ Relative Conductivity $(\mathbf{R C})(\boldsymbol{\%})$} \\
\cline { 2 - 3 } & Leaves & Roots \\
\hline $\mathbf{0}$ & $15.54 \pm 1.83 \mathrm{a}$ & $20.21 \pm 3.53 \mathrm{a}$ \\
$\mathbf{1}$ & $15.85 \pm 2.83 \mathrm{a}$ & $35.22 \pm 3.59 \mathrm{~b}$ \\
$\mathbf{5 0}$ & $30.30 \pm 7.81 \mathrm{~b}$ & $38.64 \pm 0.87 \mathrm{~b}$ \\
$\mathbf{1 0 0}$ & $53.95 \pm 5.07 \mathrm{c}$ & $52.10 \pm 7.73 \mathrm{c}$ \\
\hline
\end{tabular}

Error bars represent SD value $(n=3)$ and different letters indicate significant differences $(p<0.05)$.

\subsection{Antioxidant Enzyme Systems Response}

Antioxidant enzymes were analyzed in both roots and leaves, in order to study their response in scavenging of ROS during the course of external application of $\mathrm{Hg}$. SOD activities, both in leaves and roots, were inhibited gradually with the rising of $\mathrm{Hg}$ concentrations. Wholly, the SOD activities of leaves were higher than that of roots (Figure 7-1 (A) \& Figure 7-2(A)). In leaves, there was no significant decrease at 1 and $10 \mu \mathrm{M} \mathrm{Hg}$ in comparison to the control, which opposed to that at both 50 and $100 \mu \mathrm{M}$. However, SOD activities of treated plants went down to $84.5 \%, 79.3 \%, 63.8 \%$ and $59.3 \%$ orderly relative to the untreated control in roots. Concerning to POD, similar trends were showed in both leaves and roots as SOD activity. On the contrary, POD activities were apparently lower in leaves than that in roots wholly. In comparison to the control value $8.836 \mathrm{mM} \mathrm{g-1FW}$ min-1, POD activities were decreased to $8.031,6.324,4.324$ and $3.986 \mathrm{mM} \mathrm{g-1FW}$ min-1 at 1, 10, 50 and $100 \mu \mathrm{M} \mathrm{Hg}$ in leaves respectively (Figure 7-1 (B)). Correspondingly, in roots, 
those values were $26.350,23.240,19.340,13.250$ and $11.648 \mathrm{mM}$ g- $1 \mathrm{FW}$ min- 1 from 0 to $100 \mu \mathrm{M} \mathrm{Hg}$ treatment (Figure 7-2 (B)). As to CAT, the activities were suppressed profoundly by high-level $\mathrm{Hg}$ treatments in both leaves and roots (Figure 7-1 (C) \& Figure 72(C)). CAT activities in leaves decreased to $50.93 \%$ and $45.99 \%$ at 50 and $100 \mu \mathrm{M} \mathrm{Hg}$ as compared with control, and those decreased to $49.37 \%$ and $43.04 \%$ in roots separately. The activity was $0.082 \mathrm{mMg}-1 \mathrm{FW}$ min- 1 at $1 \mu \mathrm{M} \mathrm{Hg}$ in roots, which was higher than the control $0.079 \mathrm{mMg}-1 \mathrm{FW}$ min-1, although there was no statistical difference. As showed in Figure 7-1 (D) and Figure 7-2 (D), APX activities were inhibited significantly at 10, 50 and 100 $\mu \mathrm{M} \mathrm{Hg}$, in both leaves and roots. Furthermore, the activity bottom appeared at concentration of $100 \mu \mathrm{M} \mathrm{Hg}$, as 1.135 and $0.532 \mathrm{mM} \mathrm{g-1} \mathrm{FW} \mathrm{min-1} \mathrm{in} \mathrm{leaves} \mathrm{and} \mathrm{roots} \mathrm{separately.}$ However, there wasn't significance between control and $1 \mu \mathrm{M}$ level.

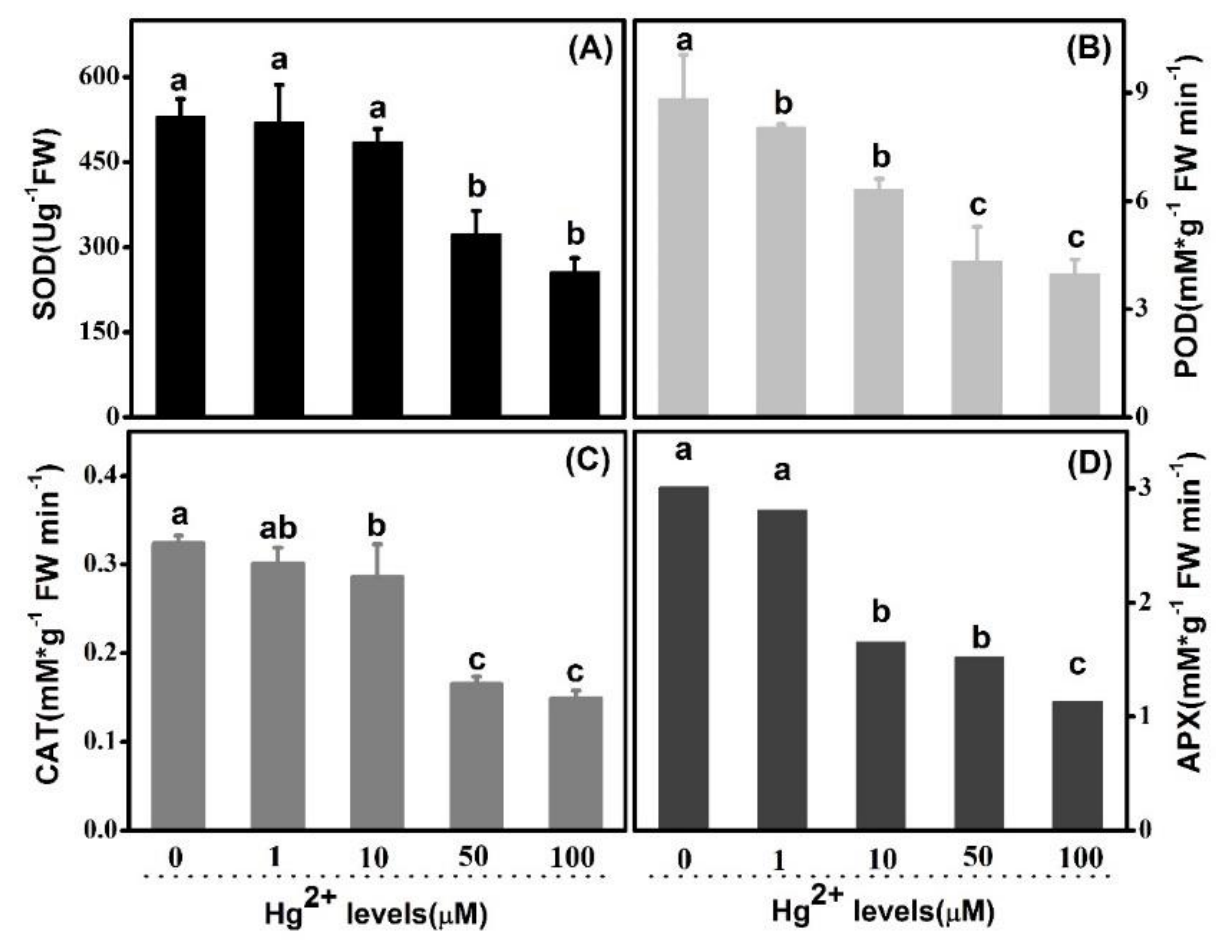

Figure 7. Effects of $\mathrm{Hg}$ on SOD, POD, CAT and APX activity in functional leaves. (A) (D): SOD, POD, CAT and APX activity is showed successively and respectively. Error bars represent SD value $(n=3)$. Different letters indicate significant differences $(p<0.05)$. 


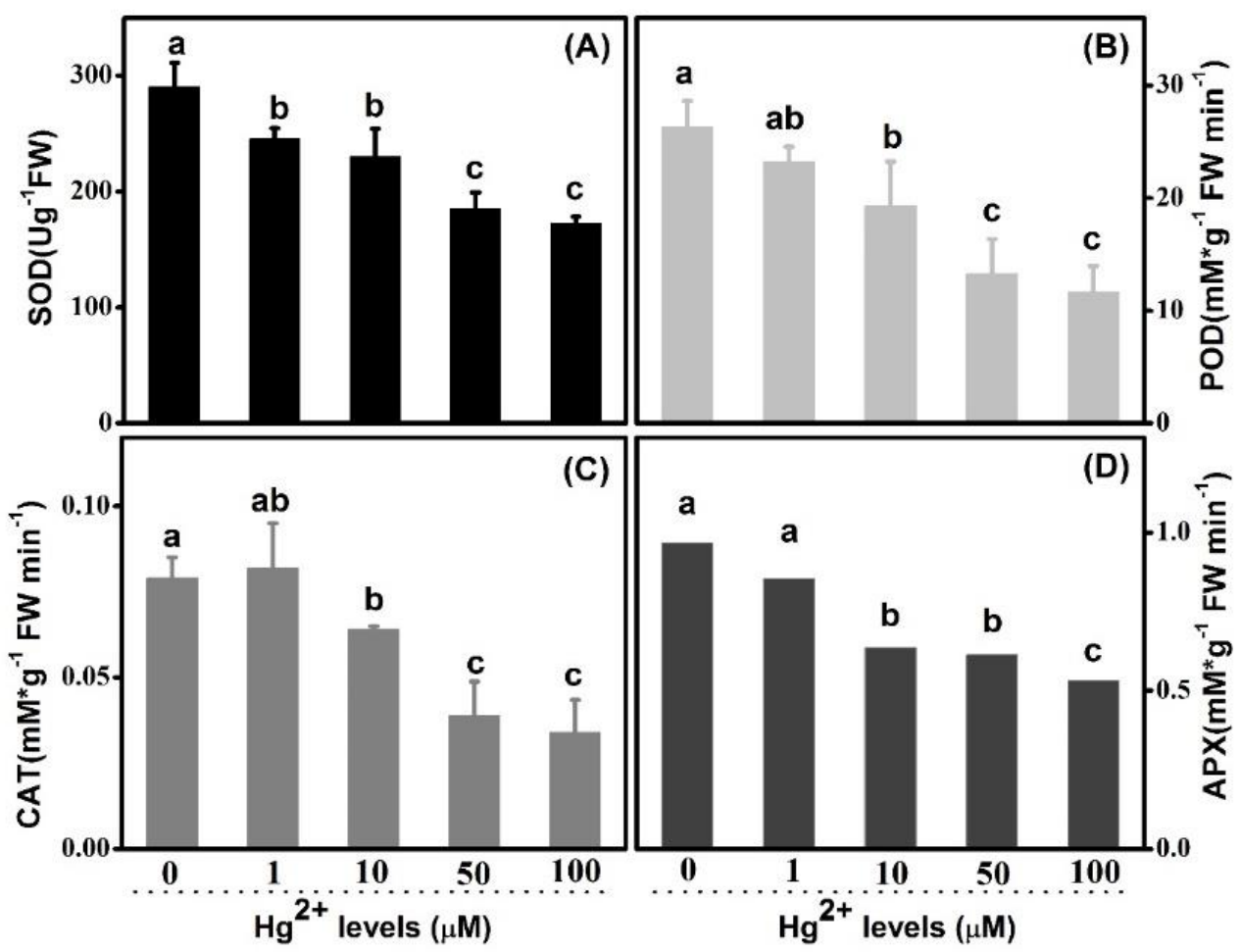

Figure 7. Effects of $\mathrm{Hg}$ on SOD, POD, CAT and APX activity in roots. (A) (D): SOD, POD, CAT and APX activity is showed successively and respectively. Error bars represent SD value $(n=3)$. Different letters indicate significant differences $(p<0.05)$.

\section{Discussion}

Mercury (Hg), as a highly toxic non-essential element and its dispersion in the environment, is considered as a serious environmental problem for its persistent character (Liu et al. 2010). Unlike most metals that function as nutrients, $\mathrm{Hg}$ has no known physiological action, so it is not metabolized by most organisms (Suszcynsky and Shann 1995). Knowledges in terms of the toxic effects of $\mathrm{Hg}$ in plants may be conducive to the general understanding on the primary toxicity mechanism and the tolerant characters in living organisms such as upland cotton. In order to evaluate the phytotoxicity raised by Hg stress in the cotton, the indicators such as the noted effects of elevated levels of $\mathrm{Hg}$ on seed germination, as well as biomass, leave features, photosynthesis pigments, gas exchanges parameters, MDA contents, relative conductivity and activities of antioxidant enzymes, were studied.

\subsection{Seeds Versus Seedling Plants, Exhibited Higher Tolerance to Hg Toxicity}

Seed germination and seedling growth are convenient and simple end-points to be employed for evaluating the toxicity of pollutants to higher plants at the early stages, which are associated with biomass directly (Chen et al. 2010). In the present study, a wild range of $\mathrm{Hg}$ concentration treatment from 0 to $10000 \mu \mathrm{M}$ was chosen for detection of tolerance on germination. The results on germination indicated that cotton seed was able to bear extra-high $\mathrm{Hg}$ concentration stress. Seed germination rate maintained over $80 \%$ although the $\mathrm{Hg}$ concentration as much as $1000 \mu \mathrm{M}$. Additionally in this high concentration, the seed color was altered rarely despite the elongation of seed shoot repressed in some extent. On the contrary, significant differences were easily to be detected on fresh or dry weight of both leave and roots separately in the even $10 \mu \mathrm{M}$ treated plants, compared to the relevant controls. As a consequence, cottonseeds exhibited much more tolerance to $\mathrm{Hg}$ stress, in comparison with the seedling plants. $50 \mu \mathrm{M} \mathrm{Hg}$ stress never affected the seed 
germination of Quercus ilex, but the root fresh root fresh weight and longest root length was easy to be depressed even by $5 \mu \mathrm{M} \mathrm{Hg}$ (Rodriguez-Alonso et al. 2019). Ling et al. (2010) reported that seed germination didn't be repressed at $100 \mu \mathrm{M} \mathrm{Hg}$ concentration in four kinds of vegetables including cabbage (Brassica rapa), cole (B. napus), head cabbage (B. oleracea) and spinach (Spinacia oleracea). Additionally, the wheat seed germination rate decreased by just approximate $10 \%$, under the $\mathrm{Hg}$ concentration as high as $1000 \mu \mathrm{M}$ (Popa et al. 2007). In present experiments in seedlings, its growth seemed to be inhibited only 10 $\mu \mathrm{M}$ Hg. It's obvious that Hg2+ are apt to be aborted by cotton root and subsequently transported to the whole plant. Our results is consistent with documented species. It's cleared that either woody or herbal plant showed relative more tolerance and sensitivity to $\mathrm{Hg}$ environment in seeds and plants respectively. Seed, as the key energy bank to organism survive, store amount of nutrition and process stronger vigor comparing with other organs, probably confer the ability to face the change on environment involving heavy metal. Roots are the primary organ to contact the $\mathrm{Hg}$, which could be distributed overall plant via the phloem. Phytotoxicity of $\mathrm{Hg}$ resulted from loss-of- function on targeted aquaporin, thus this protein family in cotton are sensitive to $\mathrm{Hg}$.

\subsection{Damage of Photosynthesis Resulting From Hg Toxicity Accounted for the Sick Growth}

Plant growth is the function in terms of cell wall extensibility, osmotic potential, water conductivity, and threshold turgor among other factors. Growth does not occur, when these agents are insufficient (Oncel et al. 2000). Decrease in seedling growth involving biomass, has been well documented in plants under Hg stress. That might be attributed to the lack of essential metal such as Fe, S and $\mathrm{Zn}$ and decreasing photosynthesis as $\mathrm{Hg}$ poison (Lenti et al. 2002). As inhibition on growth in respond to mercury toxicity in upland cotton, a similar response has also been detected in soybean (Glycine max), radish (Raphanussativus), tomato (Solanum lycopersicum) and other plants (Ketavarapu et al. 2007; Shanker et al. 1996). Hg also damaged photosynthetic pigments, which represented on declining of contents of chlorophyll. It was reported that heave metal depresses chlorophyll formation via interfering with protochlorophyllide production (Ci et al. 2010). HM might be also replaced the $\mathrm{Mg}$ from chlorophyll molecules in green plants (Rodríguez et al. 2009), thereby chlorophyll pigments reduces the photosynthetic efficiency undoubtedly.

The leaf gas exchange study indicated that photosynthetic parameters, referring to Gs, Pn and Ci, were associated with the inhibition of growth due to mercury stress. Those was reported in plants such as white lupin (Lupinus albus L.), rice (Oryza sativa L.) and Arabidopsis (Arabidopsis thaliana) (Chen et al. 2012; Ones et al.2013; Sobrino-Plata et al. 2014). In addition, these agree with our results that rising in intercellular CO2 concentration and falling in both stomatal conductance and $\mathrm{CO} 2$ assimilation rate due to increasing $\mathrm{Hg}$ levels. Thus, reduction of biomass under $\mathrm{Hg}$ stress may be the consequence of reduction in photosynthesis pigments and following blocking of photosynthesis. Declined Pn maybe result from the inhibition of relevant reaction steps in Benson-Calvin cycle and Rubisco activity influenced by these contaminants. Moreover, decrease in Pn could be on account of stomatal closing.

\subsection{Decrease on Integrity of Membrane Symbolled Cellular Injure Resulting From Hg Toxicity}

Being analogous to other abiotic stress, that HMs damage membrane is largely mediated via membrane lipid peroxidation, leading to electrolyte leakage (Chaudhuri et al. 1993). It's reported that increase in MDA contents in response to $\mathrm{Hg}$ stress has been detected both in leaves and roots from Medicageo sativa and other plants (Ortega-Villasante et al.). Significant accumulations of MDA content were observed both in leaves and roots from treatments which were more than $10 \mu \mathrm{M} \mathrm{Hg}$ concentration, in upland cotton plants. These results implicate that the membranes are injured in consequence of reactive oxygen species, as cotton seedlings are contaminated by high $\mathrm{Hg}$ levels. Rising of percentage in 
regard to electrolytic leakage has been observed both in the leaves and roots of upland cotton seedling treated with higher than $10 \mu \mathrm{M} \mathrm{Hg}$ concentration as well. It is concluded that root, rather than leaf, is more sensitive to $\mathrm{Hg}$ stress, resulting from that significant variance were detected in $1 \mu \mathrm{M} \mathrm{Hg}$ level in roots but not in leaves, as compared with the controls respectively, which in agreement with the result of SOD. The sensitivity to $\mathrm{Hg}$ stress was relatively serious in roots as compared to leaves, which might happen be attributed to $\mathrm{Hg}$ accumulation in roots is faster as exposed $\mathrm{Hg}$ iron directly. Happening of lipid peroxidation resulting from $\mathrm{Hg}$ stress has been reported in many plants, and Mishra et al. (1999) have found increase both of MDA and electrical conductivity in Oryza sativaby treated with $\mathrm{Hg}$ concentration, which in line with our results in upland cotton (Mishra and Choudhuri 1999).

$\mathrm{Hg}$ disturbed cellular redox equilibrium involving depression on activities of antioxidant enzyme system

As a transition element, oxidative stress can be induced by $\mathrm{Hg}$ in consequence of excess production of reactive oxygen species (ROS) in plants, leading to alternative antioxidant enzymes activities, lipid peroxidation and ion leakage (Zhou et al. 2007). Plants, with a set of potential mechanisms, might be associated with metal detoxification at the cellular level, and tolerance in plant is showed to HMs. The generation of ROS induced by $\mathrm{Hg}$ triggers influences activation of components in antioxidative defense system in plants, as consists of both the enzymatic system which including SOD, POD, APX, CAT and others, and the non-enzymatic system containing some low-molecular-weight antioxidants such as glutathione and ascorbic acid etc. In a whole, Exposure to higher concentrations of $\mathrm{Hg}$ concerning 50 and $100 \mu \mathrm{M}$, altered the activities of all four sort of antioxidant enzymes both leaves and root, in which $\mathrm{Hg}$ ions at low level $(1 \mu \mathrm{M})$ did not lead to significant alternation although, as compared with the controls respectively. To conclude, relevant activities of antioxidant enzymes are suppressed just under higher $\mathrm{Hg}$ concentration, while lower $\mathrm{Hg}$ treatment. The enzymatic antioxidant SOD, as the first enzyme in the detoxifying process, is considered to be an essential component among antioxidant defense system in plants. Root is more sensitive to $\mathrm{Hg}$ than that in leaf, as a resulting from that more significant variances, in terms of SOD, were detected in roots rather than in leaves in lower $\mathrm{Hg}$ levels including 1 and $10 \mu \mathrm{M}$. The changes in activity of POD have been observed under serious Hg levels, the trend in leaves is in line with that in roots, thus it is hypothesized that POD activity might be influenced in leaf and root approximately. Regarding with CAT, the activity was inhabited by $\mathrm{Hg}$ levels both in leaves and roots in a whole, while that was slightly enhanced in $1 \mu \mathrm{M} \mathrm{Hg}$ concentration in roots. It shows that CAT activity could be triggered by the lower Hg concentration in roots in some extent. It has been well documented that sorts of heave metal with low concentration stimulated activities of antioxidant enzymes, differing from the sort of the enzymes, $\mathrm{Hg}$ concentration levels and plants species (Israr and Sahi 2006; Pedron et al. 2011; Moreno-Jiménez et al.; Sahu et al. 2012). In respond to Hg stress, activity of APX was exhibited parallel trends with that of POD both in leaves and roots. Whether direct linkage exists between POD and APX in respond to Hg stress in upland cotton should be further studied.

\section{Materials and Methods}

\subsection{Assay on Seed Germination}

Matured uniform-sized seeds of upland cotton standard species Texas-Marker-1 (TM-1) were de-coated and sterilized by $70 \%$ ethyl alcohol for $5 \mathrm{~min}$, and then treated by $0.1 \%(\mathrm{w} / \mathrm{v}) \mathrm{HgCl} 2$ for $5 \mathrm{~min}$. They were thoroughly washed with distilled water for more than 4 times. Aiming at examining mercury tolerance extent in upland cotton, a wider range of concentration gradient were employed in germination experiments via $0,1,10$, 100,1000 and $10000 \mu \mathrm{M}$ and in the form of $\mathrm{HgCl}$. Every 20 seeds allocated into flasks with different mercury salt concentration. The flasks were placed in dark conditions in 
orbital shaker at $120 \mathrm{rpm}$ at $30^{\circ} \mathrm{C}$. The percentages of seeds germination were counted every 24 hours for 3 times in total.

The germination rate was calculated as the formula:

$$
\text { GR }(\%)=\frac{\text { means of germmination seeds }}{\text { means of total seeds }} * 100(1
$$

\subsection{Investigation on Growth and Mercury Distribution}

The germinating seeds were kept in dark room at $28 \pm 2{ }^{\circ} \mathrm{C}$ for 3 days, and then the baby seedlings were transferred to hydroponic solution condition (1/8 Murashige \& Skoog concentration) before emergence of true leaf. The seedlings were permitted to grow for 2 weeks in the hydroponic media and the solution were refreshed every 2 days. The 15 days old seedlings were treated by $\mathrm{HgCl} 2$ for a week. In this experiment, the concentrations treated were chosen as $0,1,10,50,100 \mu \mathrm{M}$ according to the germination performance responding to the previous wider dose border. Fresh and dry roots, stems and leaves were weighted from 3 individuals as a replicate. The inhibitory extent in seedling growth evaluated by inhibitory rate (RI), referring the following formula (2). To determine mercury content, approximate $0.2 \mathrm{~g}$ fresh samples were proceeded by nitric acid digestion for upcoming mercury element quantification by Atomic Fluorescence Spectrometer referring to (Lin et al. 2019). Mercury concentrated in tissues and translocation calculated by formulas (3) and (4).

$$
\begin{gathered}
\text { Inhibitory Rate }(\mathrm{IR})=\frac{\text { Weight }(\text { Control })-\text { Weight }(\text { Treated })}{\text { Weight }(\text { Control })} \\
\text { Concentration Index }(\mathrm{CI})=\frac{\text { Hg contents in treated plant part }}{\text { Hg contents in the control }} \\
\text { Translocation Factor }(\mathrm{TF})=\frac{\text { Hg contents in shooters }}{\text { Hg contents in roots }}
\end{gathered}
$$

\subsection{Measures of Pigments and Gas Exchanges in Leaves}

Measurement of chlorophyll pigments was conducted according to the protocol of Porra et al. (1989). To determine chlorophyll a and chlorophyll $b$ and total chlorophyll contents, reaction solution was made using pure acetone, pure ethanol and distilled water were mixed in the ratio of 4.5: 4.5:1. The $0.5 \mathrm{~g}$ small leaf pieces were taken in a $25 \mathrm{ml}$ tube and placed in dark until the color of the sample convert into white. Values of OD663 and OD645were read by UV-spectral. Chlorophyll contents were determined using the following formulae:

$$
\begin{array}{r}
\text { Chl. (a) (mg/L) }=9.78 \mathrm{OD}_{663-} \text { 0.99OD }_{645}(5) \\
\text { Chl. (b) }(\mathrm{mg} / \mathrm{L})=21.43 \mathrm{OD}_{645}-4.65 \mathrm{OD}_{663}(6) \\
\text { Chl. (t) }=\text { Chl. (a) }+ \text { Chl. (b) (7) }
\end{array}
$$

Where Chl. (a), Chl. (b) and Chl. (t) is abbreviated from chlorophyll a, chlorophyll b and total chlorophyll respectively.

Gas exchange parameters, including $\mathrm{CO} 2$ assimilation rate (Pn), stomatal conductance $(\mathrm{Gs})$ and the intercellular $\mathrm{CO} 2$ concentration $(\mathrm{Ci})$ were determined by an infrared gas analyzers portable photosynthesis system (LI-COR 6400, Lincoln, NE, USA), using third fully expanded leaves. The measurement was conducted during 10.00-11.00 A.M. maintaining the air temperature, air relative humidity, photosynthetic photon flax density (PPFD), and CO2 concentration at $25^{\circ} \mathrm{C}, 75 \%-85 \%, 1000 \mu \mathrm{molm}-2 \mathrm{~s}-1$ and $400 \mu \mathrm{molm}-2 \mathrm{~s}-$ 1 respectively

\subsection{Assay on Malondialdehyde (MDA) Content and Electrolyte Leakage (EL)}

Melondialdehyde (MDA) contents were determined according to the protocol describe by (Zhou et al. 1998). Briefly, 0.5g root or leaf samples were homogenized in tube with $10 \mathrm{ml} 0.5 \% \mathrm{TBA}$, followed by heating the homogenate at $95^{\circ} \mathrm{C}$ for $30 \mathrm{~min}$ and then 
cooled on ice immediately. After that, it was centrifuged at $5000 \mathrm{rpm}$ for $8 \mathrm{~min}$ and the supernatant was taken for measure at $532 \mathrm{~nm}$ and $600 \mathrm{~nm}$. The determination of MDA was followed as the formula:

$$
\operatorname{MDA}(\mathrm{nmol} / \mathrm{g} \mathrm{FW})=\frac{(\mathrm{OD} 532-\mathrm{OD} 600) * \mathrm{~A} * \mathrm{~V}}{\mathrm{a} * \mathrm{E} * \mathrm{~W}}
$$

Where $A=$ Volume of total reaction solution and enzyme extract, $V=$ Total volume of PBS used, $a=$ Volume of the enzyme extract used, $W=$ Fresh weight of the sample and $E=$ Constant for MDA $\left(1.55^{*} 10-1\right)$.

Leaves and roots samples were divided into small pieces of about $5 \mathrm{~mm}$ in size respectively. Electrolyte leakage (EL) was estimated referring to Dionisio-Sese and Tobita (1998) and the relative conductivity (RC) calculated via following formula,

$$
\mathrm{RC}(\%)=\frac{\text { Primary value of electric conductivity }}{\text { Value of electric conductivity via killing out }} * 100 \%
$$

\subsection{Determination of Antioxidant Enzyme Activities in Cotton Seedlings}

For the determination of antioxidant enzymes' activities, $0.5 \mathrm{~g}$ fresh samples of roots or leaves were homogenized with $3 \mathrm{ml}$ potassium phosphate buffer (BPS, $50 \mathrm{mM}$ and $\mathrm{pH}$ 7.8) in pre-chilled mortar and pestle, and then finally the volume of the homogenate was made $8 \mathrm{ml}$ with further addition of BPS. The homogenate was centrifuged for 20 minutes at $12000 \mathrm{rpm}$ at $4^{\circ} \mathrm{C}$, and the supernatant was preserved for determination of antioxidant enzymes' activities. The assays for the determination of various antioxidants were performed according to the established protocols described by Daud et al. (2013).

\subsection{Statistical Analyses}

In this study, the data were statistical analyzed basing on one-way analysis of variance (ANOVA) by SAS (Version 9) software. All test sample contains 3 replicates. Means were separated at $5 \%$ level of significance by least significant difference (LSD) test.

\section{Conclusions}

This section is not mandatory but can be added to the manuscript if the discussion is unusually long or complex. In conclusion, cottonseeds versus plants were higher tolerant to Hg stresses. Significant alternatives appeared at cottonseeds and seedlings at Hg centration of 1000 and $10 \mu \mathrm{M}$ respectively, in reviews of the means on the germination rate, growth parameters, pigments, gas exchanges, MDA, RC and actives of antioxidant enzymes including SOD, POD, CAT and APX. In plants, relative serve phytotoxicity and damage in response to $\mathrm{Hg}$ were started above $50 \mu \mathrm{M}$ level. $\mathrm{Hg}$ distribution in cotton plants affected by $\mathrm{Hg}$ levels, and root detained more $\mathrm{Hg}$ ion compared to shoots. As a whole, in cotton plants the ability to concentrate and transport $\mathrm{Hg}$ ion seemed to close the limitation at over $50 \mu \mathrm{M}$ concentrations. Overall, cotton seedlings showed some natural tolerance to $\mathrm{Hg}$ toxicity, whereas there was not apparent advantage to other filed crops like wheat (obvious phytotoxicity at above $10 \mu \mathrm{M} \mathrm{Hg}$ concentration (Sahu et al., 2012)).

Author Contributions: Conceptualization, L.M. and S.Z.; methodology, Y. Z. and Z. Z.; software, L.M.; validation, Z. Z. and H. L.; formal analysis, Y. Z. and XW. Z.; investigation, L.M. and Y. Z.; resources, L.M. and S. Z.; data curation, Y. Z., H. L., Y. L., X. L.; writing-original draft preparation, L.M., Y. Z., M. K. D. and J. C.; writing - review and editing, L.M. and S.Z.; visualization, L.M., XW. Z., XJ. Z., Z. Z.; supervision, S.Z.; project administration, L.M. and S.Z.; funding acquisition, L.M. and S.Z. All authors have read and agreed to the published version of the manuscript.

Funding: The research was financially supported by China Agriculture Research System, grant number CARS-18-25 and China Postdoctoral Science Foundation, grant number 2019M652093.

Data Availability Statement: Not applicable 


\begin{abstract}
Acknowledgments: We gratefully acknowledge supports from Analysis Center of Agrobiology and Environmental Sciences \& Institute of Agrobiology and Environmental Sciences, Zhejiang University, for in experimental equipments
\end{abstract}

Conflicts of Interest: The authors declare no conflict of interest..

\title{
References
}

1. Cao F, Wang R, Cheng W, Zeng F, Ahmed I M, Hu X, Zhang G and Wu F (2014). Genotypic and environmental variation in cadmium, chromium, lead and copper in rice and approaches for reducing the accumulation. Sci Total Environ 496:275281.

2. Chen C, Zhou Q, Bao Y, Li Y and Wang P (2010). Ecotoxicological effects of polycyclic musks and cadmium on seed germination and seedling growth of wheat (Triticum aestivum). J Environ Sci (China) 22:1966-1973.

3. Chaudhuri K, Choudhuri M A (1993). Effects of short-term $\mathrm{NaCl}$ salinity stress on free radical mediated membrane damage in two jute species. Indian J Exp Biol 3:327-331.

4. Chen Z, Pan Y, Wang S, Ding Y, Yang W and Zhu C (2012). Overexpression of a protein disulfide isomerase-like protein from Methanothermobacter thermoautotrophicum enhances mercury tolerance in transgenic rice. Plant Sci 197:10-20.

5. Ci D, Jiang D, Wollenweber B, Dai T, Jing Q and Cao W (2010). Cadmium stress in wheat seedlings: Growth, cadmium accumulation and photosynthesis. Acta Physiol Plant 32:365-373.

6. Daud M K, Quiling H, Lei M, Ali B and Zhu S J (2015). Ultrastructural, metabolic and proteomic changes in leaves of upland cotton in response to cadmium stress. Chemosphere 120:309-320.

7. Daud M K, Mei L, Azizullah A, Dawood M, Ali I, Mahmood Q, Ullah W, Jamil M and Zhu S J (2016). Leaf-based physiological, metabolic, and ultrastructural changes in cultivated cotton cultivars under cadmium stress mediated by glutathione. Environ Sci Pollut R 23:15551-155564.

8. Daud, Ali S, Variath M T and Zhu S J (2013). Differential physiological, ultramorphological and metabolic responses of cotton cultivars under cadmium stress. Chemosphere 93:2593-2602.

9. Dionisio-Sese M L and Tobita S (1998). Antioxidant responses of rice seedlings to salinity stress. Plant Sciences 1998:1-9.

10. Han F X, Banin A, Su Y, Monts D L and Plodinec J M (2002). Industrial age anthropogenic inputs of heavy metals into the pedosphere. The Science of Nature 89:497-504.

11. Han F X, Su Y, Monts D L, Waggoner C A and Plodinec M J (2006). Binding, distribution, and plant uptake of mercury in a soil from Oak Ridge, Tennessee, USA. Sci Total Environ 368:753-768.

12. Heaton A C P, Rugh C L, Wang N and Meagher R B (2005). Physiological responses of transgenic merA-Tobacco (Nicotiana tabacum) to foliar and root mercury exposure. Water, Air, \& Soil Pollution 161:137-155.

13. Israr M and Sahi S V (2006). Antioxidative responses to mercury in the cell cultures of Sesbania drummondii. Plant Physiol Bioch 44:590-595.

14. Jiang Y, Lu Y and Zhu S (2006). Advance in studies of the mechanism of salt tolerance and controlling of salt damage in upland cotton. Cotton Science 18:248-254.

15. Pedron F, Petruzzelli G, Barbafieri M, Tassi E, Ambrosini P and Patata L (2011). Mercury mobilization in a contaminated industrial soil for phytoremediation. Commun Soil Sci Plan 42:2767-2777.

16. Ketavarapu S, Yathavakilla V and Caruso J A (2007). A study of Se-Hg antagonism in Glycine Max (soybean) roots by size exclusion and reversed phase HPLC-ICOMS. Anal Bioanal Chem 389:715-723.

17. Khan M D, Mei L, Ali B, Chen Y, Cheng X and Zhu S J (2013). Cadmium-Induced upregulation of lipid peroxidation and reactive oxygen species caused physiological, biochemical, and ultrastructural changes in upland cotton seedlings. Biomed Res Int 2013:1-10.

18. Lenti K, Fodor F and Boddi B (2002). Mercury inhibits the activity of the NADPH: Protochlorophyllide oxidoreductase (POR). Photosynthetica 40:145-151.

19. Li L, Li J R, He Q L, Zhu S J and Chen J H (2014). Nutrients, ultra-structures, and Cd subcellular localization in the cottonseeds of three upland cotton cultivars under Cd stress. J Soil Sci Plant Nut 14:278-291.

20. Lin H, Santa-Rios A, Barst B D, Basu N, Bayen S (2019). Occurrence and bioaccessibility of mercury in commercial rice samples in Montreal (Canada). Food Chem Toxicol 126, 72-78.

21. Ling T, Fangke Y and Jun R, 2010. Effect of Mercury to Seed Germination, Coleoptile Growth and Root Elongation of Four Vegetables. Res J Phytochem, 4: 225-233.

22. Liu D, Wang X, Chen Z, Xu H and Wang Y (2010). Influence of mercury on chlorophyll content in winter wheat and mercury bioaccumulation. Plant Soil Environ, 56 (3): 139-143

23. Maggio A and Joly R J J (1995). Effects of Mercuric Chloride on the Hydraulic conductivity of tomato root system. Plant Physiol:331-335.

24. Mei L, Daud M K, Ullah N, Ali S, Khan M, Malik Z and Zhu S J (2015). Pretreatment with salicylic acid and ascorbic acid significantly mitigate oxidative stress induced by copper in cotton genotypes. Environ Sci Pollut R 22:9922-9931.

25. Mishra A and Choudhuri M A (1999). Effects of aslicylic acid on heavy metal-induced membrane deterioration mediated by lipoxygenase in rice. Biol Plantarum 42:409-415. 
26. Moreno-Jiménez E, Alosa J P, Esteban E and Carpena-Ruiz R O (2007). Mercury accumulation and resistance to mercury stress in Rumex induratus and Marrubium vulgare grown in perlite. J Plant Nutr Soil Sc:485-494.

27. Oncel I, Kele Y and Ustün A S (2000). Interactive effects of temperature and heavy metal stress on the growth and some biochemical compounds in wheat seedlings. Environ Pollut 107:315-320.

28. Ones M Q, Ruiz-Díez B, Fajardo S, López-Berdonces M A and Higueras P L (2013). Lupinus albus plants acquire mercury tolerance when inoculated with an Hg-resistant Bradyrhizobium strain. Plant Physiol Bioch 73:168-175.

29. Ortega-Villasante C, Rellan Alvarez R N, Francisca F Del C, Carpena-Ruize R N O and Herna Ndez L E (2005). Cellular damage induced by cadmium and mercury in Medicago sativa. J Exp Bot 56:2239-2251.

30. Popa K, Murariu M, Molnar R, Schlosser G, Cecal A, Drochioiu G (2007). Effect of radioactive and non-radioactive mercury on wheat germination and the anti-toxic role of glutathione. Isotopes Environ Health Stud 43(2):105-16.

31. Rodriguez-Alonso J, Sierra MJ, Lominchar MA, Millan R (2019) Effects of mercury on the germination and growth of Quercus ilex L. seedlings. Environ Sci Pollut Res 26:30930-30940.

32. Rodríguez E, Peralta-Videa J R, Israr M, Sahi S V, Pelayo H, Sánchez-Salcido B and Gardea-Torresdey J L (2009). Effect of mercury and gold on growth, nutrient uptake, and anatomical changes in Chilopsis linearis. Environ Exp Bot 65:253-262.

33. Sahu G K, Upadhyay S and Sahoo B B (2012). Mercury induced phytotoxicity and oxidative stress in wheat (Triticum aestivum L.) plants. Physiology and Molecular Biology of Plants 18:21-31.

34. Shanker K, Mishra S, Srivastava S, Srivastava R, Daas S, Prakash S and Srivastava M M (1996). Effect of selenite and selenate on plant uptake and translocation of mercury. Plant Soil 183:233-238.

35. Sobrino-Plata J, Meyssen D, Cuypers A, Escobar C and LE Hernández (2014). Glutathione is a key antioxidant metabolite to cope with mercury and cadmium stress. Plant Soil 377:369-381.

36. Suszcynsky E M and Shann J R (1995). Phytotoxicity and accumulation of mercury in tobacco subjected to different exposure routes. Environ Toxicol Chem 14:61-67.

37. Zhang W and Tyerman S D (1999). Inhibition of water channels by $\mathrm{HgCl} 2$ in intact wheat root cells1. Plant Physiol 120:849858.

38. Zhou W, Leul M and Leul M (1998). Uniconazole-induced alleviation of freezing injury in relation to changes in hormonal balance, enzyme activities and lipid peroxidation in winter rape. Plant Growth Regul 26:41-47.

39. Zhou Z S, Huang S Q, Guo K, Mehta S K, Zhang P C and Yang Z M (2007). Metabolic adaptations to mercury-induced oxidative stress in roots of Medicago sativa L. J Inorg Biochem 101:1-9. 